\title{
Violência contra a mulher e a Lei Maria da Penha ${ }^{1}$
}

\author{
Violence Against Women and the Law Maria da Penha
}

\begin{abstract}
Jozi Rubia Ingnácio Duarte ${ }^{2}$
Ana Claudia Duarte Pinheiro ${ }^{3}$

Deborah Ĺdia Lobo Muniz ${ }^{4}$

Simone Brun ${ }^{5}$
\end{abstract}

\section{Resumo}

0 presente artigo tem como objetivo adentrar no campo jurídico da defesa da mulher brasileira, contra a violência dos mais variados tipos que ela vem sofrendo com o passar dos tempos, analisa a legislação vigente bem como as práticas jurídicas em defesa da mulher e o impacto da lei Maria da Penha.

Palavras Chave: Violência; Mulher; Gênero; Direito; Maria da Penha.

\section{Abstract}

This article aims to enter the field of legal defense of Brazilian women, against violence of all kinds which it has suffered over time, analyzes the current legislation and legal practices in favor of women and the impact of the law M aria da Penha.

Keywords: Violence, Women, Gender, Law, M aria da Penha.

\section{Introdução}

O tema a ser apresentado neste artigo é a violência contra mulher, abordando desde a sua defesa até o destaque da importância de se dar maior atenção a este tipo de

\footnotetext{
${ }^{1}$ Artigo retirado do Trabalho de Conclusão de Curso cujo título é VIOLÊNCIA CONTRA A MULHER E A LEI MARIA DA PENHA, apresentado como requisito parcial para obtenção do grau de bacharel.

${ }^{2}$ Bacharel do 50 ano/2007 de Direito do Centro Universitário Filadélfia - UNIFIL, Londrina-Pr.

${ }^{3}$ Mestre de Direito Negocial pela UEL, professora da disciplina de Direito Ambiental da Universidade Estadual de Londrina - UEL e do Centro Universitário Filadélfia - UNIFIL Londrina-Pr. - orientadora do artigo e membro da banca examinadora.

${ }^{4}$ Mestre em Direito Estado e Cidadania pela Universidade Gama Filho - RJ, professora de Ética das Profissões Jurídicas do Centro Universitário Filadélfia - UNIFIL, Londrina-Pr. Membro da banca examinadora.

${ }^{5}$ Mestre de Direitos Humanos do Centro Universitário Filadélfia - UNIFIL e FACCAR, Londrina-Pr. Orientadora do Trabalho de Conclusão de Curso que deu origem ao artigo.
} 
comportamento tão comum no Brasil. 0 ponto culminante do trabalho se dá com a análise do impacto da lei Maria da Penha, cujo histórico mostra a sensibilidade do legislador a um problema específico, mas que foi reconhecido como uma ferida social que envergonha toda a sociedade e alcança todos os níveis sócios econômicos.

A lei 11.340 entrou em vigor em 22 de setembro de 2006, e é conhecida como Lei Maria da Penha, nome de uma das vítimas da violência doméstica, neste caso praticada pelo então marido. Sua missão é proporcionar instrumentos adequados supostamente mais eficazes no combate à violência contra mulher. Tal comportamento é também chamado de violência de gênero - relação de poder que historicamente impõe

desigualdades entre homem e mulher, numa condição de subordinação, normalmente da segunda em relação ao primeiro. É uma das mais preocupantes formas de violência porque, muitas vezes, a vítima dorme com o inimigo.

Vale ressaltar que referido instrumento legal tem sido tema de discussão na esfera jurídica em razão de suposta inconstitucionalidade, porém a lei não se restringe apenas à proteção do chamado "sexo frágil" , ao contrário, poderá ser invocada por qualquer pessoa que sofra violência em âmbito doméstico.

Para a vítima o sofrimento passa por etapas como a coação moral, psicológica e física e a submissão ocorre, por amor, por vergonha e, finalmente por medo decorrente de uma historia que não despreza, como argumento principal, a violência, quase sempre mascarada do início e depois ao longo do tempo se escancara para a família, para os amigos e para o restante da sociedade.

\section{Violência contra a mulher}

Gênero é um elemento que não faz parte do capital genético da pessoa e sim, da sua bagagem sócio-cultural, política e histórica (pessoal e coletiva). É uma maneira de referir-se à organização social das relações entre os sexos. E, ao longo deste estudo detecta-se que não são as diferenças naturais e biológicas entre os dois sexos que determinam o papel que devem desenvolver na sociedade, pois os modelos de comportamento são construídos culturalmente.

A premissa a sustentar este conceito é a de que todas as pessoas e também as organizações participam de um conjunto de relações de gênero e desde muito cedo são 
socializadas neste aspecto. Com efeito, reproduzem, muitas vezes sem perceber, ideologias e práticas sobre as relações de gênero ao longo da vida.

Os estudos realizados evidenciam que a Lei Maria da Penha se apresenta por meio de penas consideradas de maior impacto na tentativa de diminuir ou, ao menos inibir a este ilícito penal que consome a sociedade brasileira.

0 reconhecimento dos direitos da mulher, reflete uma história de lutas, perdas e conquistas ao longo do tempo. Só para se ter uma idéia o Código Civil - CC de 1916, que vigorou até 2002, imprimia à mulher uma condição de subordinação que se iniciava com o pai, e com o casamento, era transferida ao marido. Sequer tinha direito ao voto. Portanto, à mulher não eram conferidos direitos mínimos como a realização de uma transação bancária, ou inserir-se no mercado de trabalho, ou desenvolver-se academicamente.

A legislação, refletindo os valores do inicio do século XX, impôs severa punição à mulher considerada desonesta, oportunizando ao homem a possibilidade de anular 0 casamento se constatasse sua não virgindade. Como se não bastasse, ainda que a figura do adultério estivesse tipificada no Código Penal - CP atingindo tanto o homem quanto a mulher, é possível comprovar que as maiores conseqüências atingiam principalmente estas. Exemplo disto está estampado nos próprios tribunais brasileiros que absolveram ao longo de décadas, só para citar o século XX, homens que mataram suas mulheres em "legítima defesa da honra".

Importa destacar neste momento, os estudos de Venosa (2004) e Negrão (2000) que apontam as formas mais comuns de violência contra a mulher:

Violência Física - uso da força física que pode causar lesõesexternas ou internas.

Violência Psicológica - agressão emocional por atitudes ou palavras que causem a diminuição da mulher, perante as demais pessoas da família, amigos e outros. Sua estrutura é atacada diretamente o que lhe ocasiona sentimento de inferioridade. No âmbito familiar manifesta-se através de ciúmes, e injurias. 0 objetivo da agressão psicológica é diminuir socialmente a mulher.

Violência Sexual - todo ato no qual uma pessoa por meio de poder ou força física, coerção intimidação psicológica obriga uma outra a manter relação sexual contra a 
sua vontade. Ocorrem outras situações como estupro, sexo forçado no casamento, abuso sexual.

Segundo Nickhorn (2003, p. 45)

0 amadurecimento da mulher e a continua luta para fazer valer seus direitos são finalmente reconhecidos pelo Código Civil Brasileiro, o qual entrou em vigor em 2002 vindo substituir leis antigas e obsoletas, datadas de 1916. Não veio antecipar nenhum comportamento social, mas regulamentar o que já estava consumado. Desde aquela época a mulher podia estudar, ter profissão, ser independente, embora não estivesse reconhecido em Lei. Podemos entender assim, que a sociedade muda mais rápido que a lei. Não existe mais instituição de direito baseado no sexo das pessoas. Com o advento dessa lei, foi substituída a palavra "homem" por "pessoa".

Assim, atualmente, amparada legalmente por medidas protetivas do Estado em obediência aos Tratados e Convenções dos quais o Brasil é signatário, a mulher busca alinhar-se aos homens no mesmo patamar, o que significa igualdade no compromisso pela manutenção da família no que se refere a sustento e educação dos filhos assim como no espaço profissional e social.

\section{Aspectos históricos}

Relatos históricos apontam para a luta da humanidade pelo reconhecimento de direitos. Wolkmer aponta os direitos de primeira dimensão - aqueles direitos individuais ligados à liberdade, igualdade, propriedade, segurança e as diversas formas de opressão. "São direitos inerentes a individualidade, tidos como atributos naturais, inalienáveis, imprescritíveis, que por serem de defesa e serem estabelecidos contra o Estado, têm especificidade de direitos negativos". A conformação da sociedade atual tem como uma de suas maiores influências a busca incessante de melhores condições de vida que certamente implicam no reconhecimento e na concessão destes direitos.

A faraó Hatshepsut viveu no século XV a.C., governou o Antigo Egito durante 22 anos. Joana D'Arc século XV foi uma das mulheres mais forte que o mundo conheceu e teve um fim trágico sendo queimada viva em uma fogueira. 0 século XVIII, traz exemplos de destaque e, muitas vezes de infortúnio da mulher. Em 1792 na Inglaterra Mary Wollstonecraft escreve um dos grandes clássicos da literatura feminista - A Reivindicação dos Direitos da Mulher - onde defendia uma educação para meninas que aproveitasse 
seu potencial humano. Em 1793 na França Olympe de Gouges foi uma escritora, jornalista e feminista, conhecida pela divulgação de idéias libertárias e dos direitos das mulheres, foi guilhotinada.

Ainda que haja relato esparsos referentes à interferência feminina nos acontecimentos históricos, as mulheres, foram um dos segmentos sociais mais distanciado do exercicio de direitos. 0 ápice de sua luta por reconhecimento de direitos está marcado, principalmente, a partir da segunda metade do século XIX.

0 Brasil também conta com modelos de luta feminista. Segundo Nickhorn (2003, p. 45):

As primeiras manifestações de revolta contra a opressão aconteceram no século XIX, lideradas por mulheres brancas, bem economicamente e que haviam estudado na Europa, exceções dentro da população feminina, conforme Áurea Tomatis Peterson, em artigo na Revista M undo jovem. Para ilustrar cita o exemplo de Nísia Floresta que, tendo vivido na Europa, ao voltar para o Brasil foi abolicionista, republicana e feminista. Em 1842 promoveu no Rio de Janeiro, conferências sobre abolição e republica, denunciando a condição de ignorância da mulher [...].

Assim, o comportamento da mulher no século XIX evidencia que apesar das barreiras, ela definitivamente não suportaria as condições em que vivia até então. Estava, porém, consciente da longa caminhada que teria para alcançar e conquistar, quiçá, para sempre, seus direitos.

Somam-se exemplos, como Violante Bivar Velasco, fundadora do primeiro jornal feminino do Brasil em 1852, no qual denunciava violentamente a situação de inferioridade da mulher, afirmando inclusive que a mulher precisava primeiro tirar a venda de seus olhos para depois reivindicar direitos políticos e jurídicos.

Outros exemplos de mulheres que lutaram pela causa da emancipação das mulheres no Brasil são: a professora Francisca Senhorinha da Mota Diniz, a jornalista Josefina Álvares de Azevedo e a dentista Isabel M attos Dilon que, além de lutadoras pela causa feminina, exigiam o direito de votar, com base na Lei Saraiva Decreto n.o 8213 de 13 de agosto de 1881, que dava este direito a detentoras de curso universitário.

A Constituição Federal de 1934 acompanhando mudanças que vinham ocorrendo em todo o mundo finalmente garantiu a mulher o direito ao voto, porém ainda assim, 
muitas mulheres foram impedidas de expressar sua opinião, por seus pais ou maridos. Posteriormente quando o voto feminino tornou-se obrigatório, a mulher submetia-se à opinião daquele de quem dependia economicamente.

Em 1948 foi publicada a declaração universal dos direitos humanos que constituiu um importante ponto de partida para o despertar da consciência coletiva no sentido de nivelar direitos de liberdade e cidadania entre homens e mulheres.

Em 1962 através da lei №. 4121 a mulher casada passou de subordinada para colaboradora do marido e por intermédio da Constituição Federal de 1988 a mulher viu os seus direitos civis igualados ao do homem tanto na vida pública como na esfera privada. Há, porém, muitos exemplos de desrespeito aos preceitos constitucionais e em decorrência disto são inúmeros os casos de violação aos direitos da mulher.

Em 1993 na cidade de Viena durante a Conferência Mundial dos Direitos Humanos, a violência contra a mulher assumiu uma dimensão bastante significativa, refletindo o pensamento contemporâneo, uma vez que passou a ser considerada uma violação dos direitos humanos, decorrente tanto da omissão como da conivência do Estado.

No Brasil, além do tratamento constitucional, a consolidação dos direitos da mulher se confirmou, também mediante a legislação que incorporou outros termos e expressões, como por exemplo, o novo Código Civil de 2002 Lei ำ.5.869, e que veio a substituir a palavra homem por pessoa.

Assim a mulher é respaldada constitucionalmente e legalmente, no que se refere à chefia da sociedade conjugal segundo art. 226, $\$ 50$ da CF e art. 21 do Estatuto da Criança e do Adolescente - ECA, observando-se que o "pátrio poder", hoje substituído pela expressão "poder familiar" é exercido em igualdade de condições tanto pelo pai como pela mãe sempre na forma que dispuser a legislação civil.

Conforme Dias (2007) atualmente cerca de 79\% das mulheres são chefes de família, sendo que o maior número encontra-se em Salvador, onde o índice de violência é altíssimo.

Com advento, em 2006, da lei 11.340 - Lei Maria da Penha houve um avanço nos mecanismos de prevenção, erradicação e punição em relação à violência praticada contra a mulher, pois é certo que não poderia se manter tendo como penalidade, em muitas 
vezes, o pagamento de uma cesta básica, que ao invés de coibir tal prática, denotava tão somente à conivência ou negligência do Estado perante os direitos humanos da mulher, num fragrante de demonstração de uma sociedade machista e preconceituosa. Evidenciam-se penalidades mais gravosas na tentativa de diminuir ou ao menos inibir a ilicitude praticada contra a mulher.

Vale ressaltar que a referida lei não dá guarida apenas à mulher vítima de violência, mas também aos homens que se encontrem em situação semelhante. De tal forma, afasta-se eventual inconstitucionalidade que possa ser alegada na defesa de algozes, uma vez que não se identifica privilegio em razão de gênero.

\section{Vítima de um marido insano}

A Lei no. 11.340/2006 ficou conhecida como Lei Maria da Penha, em razão da luta de uma senhora, que clamou por justiça e inspirou uma legislação mais rigorosa, depois de ter sido vítima de seu próprio marido que tentou matá-la por duas oportunidades consecutivas e mesmo assim permaneceu ileso em sua liberdade.

Na primeira tentativa, houve a simulação de um assalto. Ele Ihe deu um tiro enquanto dormia e ela ficou paraplégica. Na segunda ele tentou eletrocutá-la. Em ambas situações, a mulher não teve chance de esboçar qualquer reação em defesa própria. Restou-lhe apenas contar com a ação estatal para tentar coibir uma nova tentativa.

Assim M aria da Penha, vítima de um marido insano e cruel, denunciou-o junto ao Ministério Público Estadual. Oito anos se passaram até a condenação à prisão, mas por intermédio de medidas protelatórias sequer cumpriu a pena. Permaneceu em liberdade 0 tempo inteiro. Entre a prática dessa dupla tentativa de homicídio e a prisão do criminoso, transcorreram 19 anos e seis meses.

Diante deu seu sentimento de injustiça e impunidade à vítima Maria da Penha juntamente com o CEJIL - Centro para a justiça e o direito internacional e CLADEM comitê latino americano e do caribe para a defesa dos direitos da mulher formularam uma denúncia à comissão interamericana dos direitos humanos da Organização dos Estados Americanos - OEA do qual o Brasil é signatário.

A comissão, após apreciar o caso concluiu pela necessidade de uma reforma no processo penal nacional com a finalidade de tornar mais efetivos os procedimentos 
judiciais penais, dando mais eficácia aos direitos fundamentais garantidos pela Constituição Federal, na medida em que promove a efetiva condenação e cumprimento da pena.

\section{A mudança legislativa}

Anterior à Lei $n^{\circ}$. 11.340, não existia lei específica para este tipo de problema. Sequer havia determinação de quais eram as formas de violência. M udanças ocorreram, portanto, no Código Penal e no Código de Processo Penal que até então apontavam apenas alguns aspectos relacionados à violência doméstica e, portanto, não se mostraram instrumentos suficientemente fortes e eficazes no combate ou desestímulo a este tipo de violência.

\section{No Código de Penal:}

Art. 43. A alínea $f$ do inciso II do art. 61 do Decreto-Lei $n^{0}$ 2.848, de 7 de dezembro de 1940 (Código Penal), passa a vigorar com a seguinte redação: Art. 61.

II- -

f) com abuso de autoridade ou prevalecendo-se de relações domésticas, de coabitação ou de hospitalidade, ou com violência contra a mulher na forma da lei específica;

0 Artigo 43 da Lei 11.340 dá nova redação à circunstância obrigatória e agravante genérica da pena prevista no artigo 61, II, f, do Código Penal, na parte final, a conduta da violência contra a mulher deverá encontrar conceituação ou adequação numa das formas previstas da lei 11.340/06 - 50 a 7ํ, que contém as disposições que determinam os vários tipos de violência contra a mulher.

Art. 44. 0 art. 129 do Decreto-Lei ํㅡ 2.848, de 7 de dezembro de 1940 (Código

Penal), passa a vigorar com as seguintes alterações:

Art. 129. 
$\S 9^{\circ}$ Se a lesão for praticada contra ascendente, descendente, irmão, cônjuge ou companheiro, ou com quem conviva ou tenha convivido, ou, ainda, prevalecendo-se 0 agente das relações domésticas, de coabitação ou de hospitalidade:

Pena - detenção, de 3 (três) meses a 3 (três) anos.

$\S 11$. Na hipótese do $\S 9^{\circ}$ deste artigo, a pena será aumentada de um terço se o crime for cometido contra pessoa portadora de deficiência. (NR).

0 artigo 44 da lei dá nova redação ao artigo 129, § 9o , do Código Penal, eleva a pena, de seis meses a um ano de detenção, para três meses a três anos de detenção, e acrescenta o parágrafo 11, que estabelece causa de aumento da pena de um terço se 0 crime for praticado contra pessoa portadora de deficiência.

\section{Código de Processo Penal:}

Art. 42. 0 art. 313 do Decreto- Lei $n^{0}$ 3.689, de 3 de outubro de 1941 (Código de Processo Penal), passa a vigorar acrescido do seguinte inciso IV:

Art. 313.

IV - se o crime envolver violência doméstica e familiar contra a mulher, nos termos da lei específica, para garantir a execução das medidas protetivas de urgência. (NR)

0 artigo 42 da lei inclui mais um inciso no artigo 313 do CPP, que trata da admissibilidade da prisão preventiva em crimes dolosos.

\section{Lei de Execuções Penais:}

Art. 45. 0 art. 152 da Lei $n^{0}$ 7.210, de 11 de julho de 1984 (Lei de Execução Penal), passa a vigorar com a seguinte redação:

Art. 152.

Parágrafo único. Nos casos de violência doméstica contra a mulher, o juiz poderá determinar o comparecimento obrigatório do agressor a programas de recuperação e reeducação. (NR)

0 artigo 45 acrescenta o parágrafo único que prevê a possibilidade de o juiz, nos casos de violência doméstica contra a mulher, determinar o comparecimento obrigatório do agressor a programas de recuperação e reeducação.

Antes desta lei os processos eram de competência dos juizados especiais criminais, lei 9.099/95 registros em termos circunstanciados, vez que eram considerados 
delitos leves e, portanto chamados de casos de menor potencial ofensivo. Assim a pena

máxima não era superior a 2 anos. A partir da vigência da lei o processo passou para competência das varas criminais onde permanecerão até que sejam criados os juizados da violência doméstica e familiar.

A partir de agora toda violência decorrente do âmbito familiar ou doméstico exige a abertura de inquéritos e as vitimas devem ser encaminhadas para 0 atendimento e proteção, o que representa um avanço na proteção de todos aqueles que se encontram em situação de risco e fragilidade.

As penas pecuniárias foram extintas e 0 agressor penalizado com 0 pagamento de multa ou cestas básicas ou detenção de 6 meses a 1 ano passa ao cumprimento de pena de detenção de 3 meses a 3 anos.

\section{Conclusão}

A Lei Maria da Penha se traduz em importante conquista para a sociedade e para as vítimas de violência familiar e doméstica, representando o reconhecimento do princípio da igualdade estatuída na Constituição Federal de 1988 e que todos têm o dever de proteger sempre, na busca constante por uma sociedade mais justa e fraterna, com oportunidade e direitos iguais para todos.

Cabe agora a cada cidadão - homem ou mulher - buscar conhecer a legislação e não deixá-la no papel, mas cumpri-la e incentivar o seu cumprimento. Esta lei deve ser incorporada ao cotidiano de cada delegacia e na mente de cada pessoa agredida, favorecendo um número maior de denúncias e a redução do silêncio pós-violência.

\section{Referências}

DIAS, M aria Berenice. A lei Maria da Penha na Justiça: a efetividade da Lei 11.340/2006 de combate à violência doméstica e familiar contra a mulher. São Paulo: Revista dos Tribunais, 2007.

NEGRAO, Télia. A rede de defesa dos direitos humanos das mulheres. Porto Alegre/Assembléia Legislativa, 2002.

NICKHORN, I.R. Mulher, questão de gênero, a construção de modelos femininos. Revista temas sociais em expressão, v.2, n.2, maio, 2003. 
VENOZA, Silvio de Salvo. Direito de família. São Paulo: Atlas, 2004.

WOLKM ER, Antônio Carlos. Introdução aos Fundamentos de uma Teoria Geral dos

"Novos" Direitos. In WOLKM ER, Antônio Carlos e LEITE, José Rubens M orato. OS NOVOS

DIREITOS NO BRASIL: NATUREZA E PERSPECTIVAS: UM A VISÃO BÁSICA DAS NOVAS CONFLITUOSIDADES JURÍDICAS. São Paulo: Saraiva, 2003. 